\title{
Implementasi Nilai-Nilai Kepedulian Lingkungan Hidup Dalam Mata Pelajaran Pendidikan Agam Islam
}

Zaky Fajar Taufiqurrahman ${ }^{1}$, Muthi'ah Hijriyah ${ }^{2}$

${ }^{1,2}$ Program Pendidikan Agama Islam, Fakultas Agama Islam, Universitas Hasyim Asy'ari

\begin{tabular}{l} 
Article Info \\
\hline Article history: \\
Received Agustus 16, 2019 \\
Accepted September 3, 2019 \\
\hline
\end{tabular}

\section{Keywords:}

Implementation

Environmental Concern

Islamic Education Subjects

\begin{abstract}
Environmental care behavior can change the environment that is initially dry to be beautiful full of lush plants that thrive and a sense of comfort for schools and school residents. While these subjects have four pillars, namely: Fiqh, Ski, Al-Qur'an Hadist, and Akidah Akhlaq, which are muttering to each other. The school has also successfully integrated formal lessons with environmental education materials. From the description above, the authors formulated the focus of the study as follows: How the values of caring, implementation, inhibiting and supporting factors in the process of growing values of environmental concern in middle school. A. Wahid Hasyim. The research uses a case study qualitative research. Data collection techniques using observation, interviews, and documentation. For data analysis techniques using: data reduction, data display, data verification. To check the validity of the data by: (1) credibility: a. extension of participation, b. perseverance of observation, $c$. triangulation, d. Negative Case Analysis, e. Using reference material, f. using member check, (2) transferability, (3) dependability, (4) confirmation. The results showed that: The value of environmental care in AWH Middle School was applied both in theory and practice, while for constraints was financing and the formation of new personalities, for supporters in this case the participation of all school members in maintaining cleanliness.
\end{abstract}

This is an open access article under the CC BY-SA license.

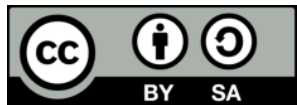

\section{Corresponding Author:}

Zaky Fajar Taufiqurrahman,

Program Studi Pendidikan Agama Islam,

Universitas Hasyim Asy'ari,

Email: mynameiszaky@gmail.com

\section{PENDAHULUAN}

Pendidikan adalah segala hal yang di lalui seorang peserta didik dengan berbagai macam cara yang dia tempuh. Pendidikan luas ini belum mempunyai sitem. Sebagai pengajar tentu saja memiliki tangung jawab dalam menyampaikan materi yang akan di ajarkan. Karakteristik pada artin luas: (1) pendidikan berlangsung sepanjang hayat, (2) ruang lingkup pendidikan adalah semua yang berada di sekitar peserta didik, (3) sebagain wujud aktifitas baik yang terstruktur maupun tidak terstruktur, (4) visi dari pembelajaran harus sinkron beserta pengalamn belajar, dan (5) terbebas dari bilik dan waktu. (Ramayulis, 2011)

Usman menjelaskan bahwa implementasi adalah bermuara pada aktiitas, aksi, tindakan, atau, adanya mekansme suatu sistem. Implementasu bukan sekedar aktifitas, tetapi suatu kegiatan yang terencana dan mencapai tujuan kegiatan (Usman, 2002). Konsep dasar lingkungan hidup ialah keterkaitan manusia dan lingkungan, di sebuah buku ditulis seperti ini "hidup manusia tergantung sekali pada lingkungannya. tanpa itu manusia tidak akan hidup. Oleh karena itu untuk menjaga kelanjutan hidup manusia tersebut, maka 
lingkungan harus di benahi sebaik-baiknya." (Aziz, 2013). Kaitan antara pendidikan Islam dengan lingkungan hidup sangat erat, hampir-hampir tak dapat dipisahkan, tapi sayang pendidikan Islam tersebut khusunya di Indonesia belum memberikan tempat dan perhatian yang serius yang lebih berarti dalam pembinaan dan pelestarian lingkungan hidup, dan juga manusia di dunia baru ini bisa membangun bagi kepentingan nasional, bangsa, dan negaranya. Tetapi, belum memperhitungkan dampak pembangunan pada kerusakan di bumi. (Salim, 2010).

Nilai-nilai tentang kepedulian lingkungan hidup tentunya sangat penting bagi siswa didik/murid. Umumnya guru banyak yang mengunakan metode mengajar menggunakan metode diskusi. Metode diskusi adalah "memberikan alternatif jawaban untuk membantu memecahkan berbagai problem kehidupan, dengan catatan persoalan yang akan di diskusikan harus di kuasai secara mendalam" (Djamarah, 2007). Menurut beberapa buku ada yang menulis seperti ini di dalam buku tersebut "banyak peranan yang di perlukan dari guru sebagai pendidik atau siapa saja yang menerjunkan diri menjadi guru" (Djamarah, 2007). Pada mata pelajaran Pendidikan Agama Islam para siswa di anjurkan agar turut serta dalam menjaga dan mencintai lingkungan. Sebagaimana bunyi hadis berikut. Sebagaimana bunyi hadis berikut:

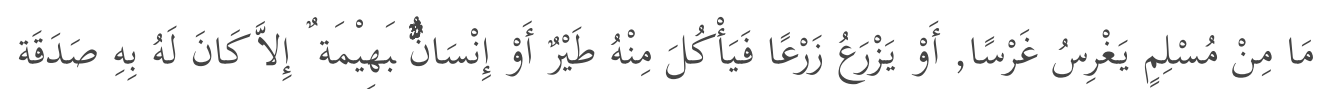

Yang artinya: Anas.r.a. berkata: Rasulullah saw. Bersabda: Tiada seorang muslim yang menanam tanaman kemudian dimakan oleh burung, manusia, atau binatang melainkan tercatat untuknya sebagai shadaah. (HR. Bukhori dan Muslim) (al-Bukhari, 2014). Penjabarnya dari hadits tersebut yaitu barang siapa yang menanam pohon(tanaman) itu tetap mendapat pahala selama tanaman itu berbuah lalu ada yang makan daripadanya (Abdul Baqi, 2005). Dengan melihat begitu pentingnya menjaga lingkungan dan sekitarnya. Karena ini adalah proyek jangka panjang yang di harapkan siswa dapat memelihara dan berpartisipasi dalam peduli lingkungan hidup.

\section{Fokus Penelitian}

Dengan Fokus Penelitian tiga yaitu: 1). Bagaimana nilai-nilai Kepedulian Lingkungan hidup dalan mata pelajaran Pendidikan Agama Islam, 2) Bagaimana implementasi Nilai-Nilai Kepedulian Lingkungan Hidup dalam Mata Pelajaran Pendidikan Agam Islam di SMP. A. Wahid Hasyim, 3) Apakah faktor-faktor penghambat dan pendukung dalam proses menumbuhkan Nilai-nilai rasa kepedulian lingkungan hidup di SMP. A. Wahid Hasyim

\section{Tujuan Penelitian}

Sesuai dengan fokus penelitian tersebut, maka tujuan penelitian ini adalah sebagai beriktu:

1. Untuk Mengetahui impelementasi nilai-nilai Kepedulian Lingkungan hidup dalam mata pelajaran Pendidiakn Agama Islam

2. Untuk mengetahui apa saja faktor-faktor penghambat dalam menumbuhkan sikap Nilai-nilai rasa kepedulian lingkungan hidup di SMP. A. Wahid Hasyim

\section{Kajian Pustaka}

\section{Kepedulian Lingkungan Hidup}

\section{a. Makna Lingkungan Hidup}

Ekosistem atau sistem ekologi adalah suatu tatanan yang tebentuk oleh interaksi antara organisme (hayati) dengan unsur-unsur nonhayati (abiotic) dalam suatu wilayah (K.E.S. Manik, 2016).

\section{b. Tujuan Kepedulian lingkungan hidup}

Adapun beberapa hasil konferensi yang telah di selenggarakan di berbagai wilayah, antaranya adalah di Tbilisi 1977. Pada pertemuan tersebut menghasilkan beberapa keputusan mengenai tujuan umum diselenggarakannya konferensi tersebut adalah sebagai berikut;

1) Untuk mendukung dan mentransparankan tentang kepedulian serta empati dalam hal yang berhubungan dengan finansial, lingkungan manusia, politik, dan ilmu lngkungan baik di pusat atau di daerah.

2) Untuk memberikan kesempatan pada setiap insan agar dapat memunculkan potensi wawasan, hasil, pandangan, kemauan, dan bisa untuk menjaga dan menata ulang sekitarnya.

3) Untuk menciptakan sebuah inovasi bagi semua elemen mahluk sosial agar saling bahu-membahu menjaga kawasan hidup (Hamzah, 2013). 
c. Sumber daya

Sumber daya terdiri dari berbagai jenis, yang di bagi menurut asal, sifat, dan kemungkinan memulihkannya. Menurut asalnya, sumber daya terbagi menjadi dua, yaitu: (1) Sumber daya buatan. (2) Sumber daya alam (Mukhtasor, 2008).

\section{Makna Pendidikan Agama Islam}

Pembelajaran adalah suatu tindakan yang di lakukan agar ada regenerasi ilmu dari para pendahulunya.

a. Tujuan dan Sasaran Pendidikan Agama Islam

Inti dari pembelajaran ini adalah agar para peserta didik selalu taat dan menjauhi segala larangan yang telah di tetapkan oleh Allah SWT (Putra dan Lisnawati, 2013). Sedangkan menurut pendapat dijelaskan bahwa target dari PAI adalah penguasaan materi tentang keagamaan mulai dari dia lahir sampai akhir hidupnya (Achmadi, 2005).

\section{b. Strategi Pembelajaran PAI}

Banyak cara yang digunakan pengajar dalam menyampaikan ilmu kepada para murid agar mereka paham dan mengerti. Seperti mengajak mereka berdiskudi dan tanya jawab ketika sesi pembelajaran di kelas.

3. Implementasi dalam Mata Pelajaran Pendidikan Agama Islam

a. Impementasi dalam Mata Pelajaran Pendidikan Agama Islam

1) Mata pelajaran Al-Qur'an dan Hadist. Contoh penggalan hadist di bawah ini:

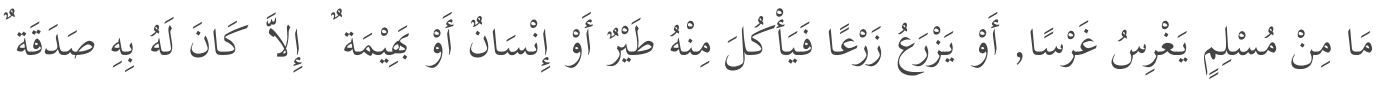

Yang artinya: Anas.r.a. berkata: Rasulullah saw. Bersabda: Tiada seorang muslim yang menanam tanaman kemudian dimakan oleh burung, manusia, atau binatang melainkan tercatat untuknya sebagai shadaah (al-Bukhori, 2014).

Contoh Penggalan Ayat Al-Qur'an di bawah ini:

$$
\text { هوَ اللَّنِي خَلَقَ لَكُْْ مَا فِي الْأْْ ضِ جَمِيعًا }
$$

Artinya: Dia-lah (Tuhan) yang telah menciptakan untuk kalian semua yang ada di bumi. (QS. AlBaqarah (2): 29). Jadi semua yang ada di bumi (darat, laut, dan udara) baik yang hidup maupun tidak hidup merupakan sumber daya yang diciptakan Tuhan untuk kita semua (Erwati, 2013).

\section{METODE}

Untuk mengupas isi dari fokus penelitian yang sudah di paparkan di bab I, maka peneliti menggunakan metode penelitian kualitatif sebagai alat untuk membedah cara apa saja yang di gunakan untuk menyajikan hasil penelitain yang sesuai dengan fokus masalah pada bab bab IV nantinya. Inti dari metode kualitatif adalah mengamati fenomena yang terjadi pada subyek yang diteliti. Di dalam penelitian yang di lakukan, peneliti menggunakan jenis penelitian studi kasus (case study) yang bertujuan untuk memfokuskan penelitian pada suatu persoalan secara intensif dan terperinci serta mempertahankan keutuhan dari ojek yang diteliti. Dan dalam penelitian ini, peneliti memilih jenis penelitian kualitatif lapangan (field research). Yang memudahkan peneliti untuk mencari data yang di perlukan untuk mendukung penelitian ini.

Latar Penelitian dalam penelitian ini adalah SMP A Wahid Hasyim Tebuireng Jombang. Alasan, peneliti memilih sekolah tersebut karena setiap mata pelajaran di sekolah tersebut sudah di implementasikan dengan materi lingkungan hidup. Jadi siswa tidak hanya belajar materi umum dan agama saja, mereka juga di beri wawasan tentang lingkungan. Data dan Sumber Data adalah hal mutlak yang harus didapatkan dalam penelitian ini. Karena itu, peneliti berusaha mencari fakta yang di kumpulkan, baik yang berupa angka maupun fenomena, sedangakan untuk sumber data (informan), peneliti telah menetapkan subyek sesuai kebutuhan penelti sebagai berikut: 1) Kepala Sekolah, 2) Waka Sekolah, 3) Guru Mapel dan 4) Siswa yang dapat membagikan informasi yang dibutuhakan pada penelitian ini,

Dalam Teknik Pengumpulan Data, peneliti menggunakan cara yang sesuai dengan metode ini, sebagai berikut: Observasi yaitu dimana peneliti langsung turun ke lapangan untuk mengamati apa yang terjadi di lapangan ketika proses penelitian. Wawancara upaya peneliti dalam mencari data melalui percakapan dua orang atau lebih mengenai fokus penelitian yang sedang di kaji oleh peneliti. Sedangkan dokumentasi sendiri adalah cara yang digunakan peneliti untuk mengabadikan suatu kejadian yang berkaitan dengan penelitian tersebut.

Pada teknik analisi data, suatu penelitian tentu membutuhkan suatu teknik analisis yang dimakudkan untuk mencari inti dan mengkaji, kemudian menarik kesimpulan dari penelitian yang telah dilakukan. 
Beberapa cara yang di pakai dalam teknik analisis data pada penelitian ini adalah: Reduksi Data, Penyajian Data, dan Penarikan Kesimpulan. Sedangkan untuk pengecakan keabsahan data di gunakan teknik Triangulasi Data, alasan teknik ini digunakan peneliti karena teknik tersebut di pakai dengan berbagai cara pada sumber yang sama.

\section{HASIL DAN PEMBAHASAN}

Sesuai dengan teknik analisi data yang diambil peneliti adalah kualitatif studi kasus dengan cara menganallisis data yang telah di kumpulkan dari para sumber data dengan menggunakan metode obserasi, wawancara dan dokumentasi. Data yang telah diperoleh dapat dipaparkan dan disajikan oleh peneliti serta dikaitkan dengan teori-teori di landasan teori dan pustaka. Di bawah ini adalah hasil penelitian tentang Implementasi Nilai-Nilai Kepedulian Lingkungan Hidup Dalam Mata Pelajaran Pendidikan Agama Islam.

Nilai-Nilai Tentang Kepedulian Lingkungan Hidup dalam Mata Pelajaran Pendidikan Agama Islam

Di SMP A. Wahid Hasyim Tebuireng Jombang mata pelajran Pendidikan Agama Islam yang membahas tantang kepedulian lingkungan hidup ada di bab Thoharoh/bersuci sesuai dengan Silabus dan RPP Pendidikan. Berikut adalah paparan silabus dan rpp kelas 7 untuk tingkat Sekolah Menegah Pertama. Ini sesuai dengan isi RPP dan Silabus pada mata pelajaran Pendidikan Agama Islam yang diajarkan pada siswa kelas VII. Sub bab atau materi yang mengajarkan tentang kebersihan terdapat pada bab Thoharoh. Pada bab tersebut diterangkan bagaimana cara bersuci dari hadast besar maupun hadast kecil. Pada bab thoharoh ini, guru lebih ditekankan untuk mempratekkan secara langsung bagaimana cara bersuci (wudhu), menyampaikan dalil-dalil tentang pentingnya bersuci dan hal-hal apa saja yang dapat membatalkan wudhu.

Sesuai dengan data yang ada diatas, yang berupa silabus dan RPP mata pelajaran Pendidikan Agama Islam siswa smp kelas 7. Kalau di smp kurikulum yang ada kaitanya dengan materi lingkungan hidup adalah materi PAI tentang thoharoh. Prakteknya sekolah ini adalah sekolah adiwiyata, fungsi dari mata pelajran Pendidikan Agama Islam adalah memberi dalil dan menumbuhkan kesadaran. Yang di gunakan adalah dalil-dalil keagamaan. Sesuai dengan Tujuan Pendidikan Agama Islam, Secara substansial tujuan Pendidikan Agama Islam (PAI) adalah mengasuh, membimbing, mendorong, mengusahakan, menumbuhkembangkan, amnesia takwa. Takwa merupakan derajat yang menunjukan, kualitas manusia bukan saja di hadapan sesame manusia, tetapi juga di hadapan Allah. Ketakwaan merupakan "high concept" dalam arti memiliki banyak dimensi dan merupakan suatu kondisi yang pencapaiannya membutuhkan upaya yang keras melewati dan melampaui tahap demi tahap. (Putra dan Lisnawati, 2013)

Dalam menumbuhkan nilia-nilai kepedulian lingkungan hidup dalam mata pelajaran Pendidikan agama islam, dapat melalui media pembelajaran yang ada. Lingkungan hidup adalah kesatuan ruang dengan semua benda, daya, keadaan, dan mahluk hidup, termasuk di dalamya manusia dan perilakunya, yang memengaruhi kelangsungan peri kehidupan dan kesajahteraan manusia serta makhluk hidup lainnya (K.E.S. Manik, 2016). Di SMP A. Wahid Hasyim sendiri ada beberapa mata pelajaran yang bisa diintegrasikan pada Pendidikan Lingkungan Hidup. Di mana materi dari mata pelajaran tersebut yang bisa diintegrasikan dengan pendiidkan lingkungan hidup adalah materi tentang thoharoh. Sesuai dengan yang diungkapkan oleh guru-guru yang mengajar siswa dan siswi kelas 7, bahwa impelmentasi nilai-nilai kepedulian lingkungan hidup dapat di pratek-kan secara langsung dalam materi pecahan Pendidikan Agama Islam yaitu Thoharoh.

Mata pelajaran yang secara umum mengajarkan inti di dalam agama islam. Dengan adanya mata pelajaran tersebut didalam kurikulum di berbagai tingkat Pendidikan menunjukkan bahwa seberapa pentingnya mata pelajaran tersebut. Di samping kurikulum yang di dalam terdapat materi yang siap di ajarkan. Di setiap mata pelajaran ada KD yang di tambahkan tentang Pendidikan lingkungan hidup yang bisa incloud dan berdiri sendiri pada semua mata pelajaran. Guru lebih sering mencontohkan dari pada memberi materi, khususnya anak kelas 7. Pendidikan sangatlah penting untuk kita kedepanya, karena pendidikan menjadi fasilitas untuk dari yang tidak paham menjadi paham, apalagi Pendidikan Agama Islam. Pendidikan Agama Islam sendiri menjadi dasar utama dalam mengamalkan ajaran-ajaran yang terkandung didalam materi mata pelajaran Pendiidkan Agama Islam. Di samping mereka belajar secara teori di sekolah maupun dipondok apa itu agama islam dan apa saja cabang dari ilmu agama islam, mereka juga harus dibekali cara mempraktekkanya dalam kehidupan mereka sehari-hari. Karena ilmu tanpa amal, itu percuma. Apa yang mereka pelajari tidak mereka gunakan. Ilmu agama adalah ilmu yang mempelajari teori dan praktek secara langsung dalam kehidupan sehari-hari. Di samping mereka belajar ilmu agama di pondok dan sekolah, mereka juga mempratekkannya dilingkungan terdekatnya seperti di kamar, sekolah dan kelas.

\section{Implementasi Nilai-Nilai Kepedulian Lingkungan Hidup di bidang studi}

Sekolah SMP A. Wahid Hasyim Tebuireng Jombang, sendiri adalah sekolah yang berbasis pesanteren 
dan adiwiyata. Jadi di dalam pembelajaran materi maupun non materi selalu di masukkan nilai-nilia/contoh baguamana cara kita amerawat lingkungan. Menurut Kepala Sekolah, alasan mengapa SMP mengikuti atau menerapkan program adiwiyata antara lain adalah "sekolah semakin maju, anak-anak menjadi semnagat waktu kegiatan bersih-bersih dan saaat kegiatan menanam teanaman di tamana dan lingkungan sekitar sekolah. Menurut Waka Sekolah, di SMP sendiri ada beberapa kegiatan yang bisa menunjang proses bagaimana cara mengimplementaasikan peduli lingkungan hidup atau yang berkaitan dengan lngkungan hidup yakni sebagai berikut:

Setiap bulan itu ada 1 kali senin bersih di setiap minggu pertama awal bulan. Kegiatan senam Bersama, yaitu kegiatan yang di ikuti anak-anak dengan mengajak mereka senam bersama kemudian setelah senam mereka di ajak bersih-bersih lingkungan sekoklah bersama. Di karenakan ligkungan SMP sendiri di kelilingi oleh tanaman-tanaman dan juga pepohonan yang sudah besar, maka dalam sehari di bersihkan dua kali untuk menjaga kebersihan lingkungan sekolah tetap terjaga. Sekolah juga melarang, terutama untuk kantin(pedagang-pedaganya) menjual yang berhubungan dengan plastik, yang bertujuan untuk menugurangi volume sampah plastik. Sholat berjamaah, kegiatan tersebut dimaksudkan untuk menanamkan sifat kesadaran akan tugas dan kewajibannya sebagai umat islam. Setiap bulan diadakan evaluasi terkait program kerja yang telah disusun sebelumnya untuk dimintai keterangan.

Di samping adanya kegiatan-kegiatan yang dijelaskan diatas, dapat di tarik kesimpulan bahwa sekolah dapat mengimplementasikan peduli lingkungan hidup di lingkungan sekolah pada khususnya. Guru secara langsung memberikan contoh di lapangan kepada siswa dan siswi apa itu peduli lingkungan dan manfaatnya. Adapun tambahan anggota yang mendukung program adiwiyata selain kegiatan diatas, mereka adalah pokja (kelompok kerja). Mereka bekerja di bawah naungan sekolah dan anggotanya terdiri dari guruguru sekolah. Dengan adanya Pokja di sekolah ini, sangat membantu sekali dalam proses berjalanya program dan bagi anak-anak, mereka jadi antusias menjadi bagian dari pokja tersebut, serta berpartisipasi dalam kegiatan pokja. Teori hanya berbicara tentang apa yang akan terjadi dan sebab akibat. Tapi praktek berbeda dengan yang mereka pelajari dikelas, Terkadang teori yang digunakan tidak singkron dengan medan di lapangan. Pada proses pelasksanaanya, sebagian besar warga di SMP A. Wahid Hasyim Tebuireng Jombang ikut berpartisipasi dalam hal seperti: ro'an bersama, proses pemuatan kompos, dan event-event adiwiyata yang di ikuti. Program Adiwiyata sendiri adalah program dari pemerinah beersama kementrian lingkungan hidup yang tertera di dalam Kesepakatan Bersama Antara Menteri Pendidikan Nasional dengan Menteri Lingkungan Hidup Nomor 03/MENLH/022012 dan 01/II/KB/2010.

\section{KESIMPULAN}

Nilai-nilai kepedulian lingkungan hidup yang terkandung dalam mapel PAI sudah sangat di perhatikan. Implementasi nilai-nilai kepedulian lingkungan hidup di unit pendidikan ini di terapkan dengan cara mengajak mereka ikut serta dalam kegiatan sekolah. Faktor penghambat di SMP A. Wahid Hasyim Tebuireng Jombang adalah biaya dan sifat rasa memiliki antar warga sekolah. Faktor pendukung di sekolah ini adalah dukungan dari berbagai pihak dan antusiasme dari warga sekolah yang dengan semangat ikut membantu terlaksananya program adiwiyata

\section{REFERENSI}

Bukhori, Imam, Shohih Bukhori. Jilid 7. Juz 2. Beirut: dar al-Kutub al-Ilmiyah, t.th Daryanto, Agung Suprihatin, Pengantar Pendidikan Lingkungan Hidup. Yogyakarta: Gava Media, 2013

Erwati. Aziz, Upaya Pelestarian Lingkungan Hidup. Yogyakarta: Pustaka Pelajar, 2013

Fu'ad Abdul Baqi, Muhammad terjemah Al-Lu'lu wal Marjan, Surabaya:PT Bina ilmu,2005

Karwati Euis dan Doni Junni Priansa, Manajemen Kelas, Classroom

Kementrian Agama RI al-qur'an dan Terjemahanya: Juz 1-30, Bandung; Manajement, Bandung: Alfabeta 2014.

Manik, K.E.S, Pengelolaan Lingkungan Hidup Jakarta: Prenadamedia Grup, 2016.

Mulyasa, Pengembangan dan Imple Emtasi Kurikulum 2013.

Muslim, Imam, Shohih Muslim. Jilid 7. Juz 1. Beirut: dar al-Kutub al Ilmiyah, t.th

Pujileksono, Sugeng. Metode Penelitian Komunikasi Kualitatif. Malang: Kelompok Instans Publishing, 2015

Ramayusli, Ilmu Pendidikan Islam. Jakarta: Kalam Mulia, 2011

Salim, Emil, Ratusan Bangsa Merusak Satu Bumi, Jakarta: PT Kompas Media Nusantara,2010.

Sanjaya, Wina, Strategi Pembelajaran Berorientasi Standar Proses Pendidikan. Jakarta PrenadaMedia Group, 2016

Soekanto, Soejono dan Budi Sulistyowati, Sosiologi Suatu Pengantar, Jakarta: PT RajaGrafindo Persada, 2015 Syarif, Herdianyah, Wawancara Observasi dan Focus Group, Jakarta: PT grafindo Persada,2015

Usman, Nurdin, Konteks Impelentasi Berbasis Kurikulum. Jakarta: PT Grafindo Persada, 2002 